\title{
Comparison of UV and high-energy ion irradiation of methanol:ammonia ice
}

\author{
G. M. Muñoz Caro ${ }^{1, \star}$, E. Dartois ${ }^{2,3}$, P. Boduch ${ }^{4}$, H. Rothard ${ }^{4}$, A. Domaracka ${ }^{4}$, and A. Jiménez-Escobar ${ }^{1}$ \\ ${ }^{1}$ Centro de Astrobiología (CSIC-INTA), Carretera de Ajalvir, km 4, Torrejón de Ardoz, 28850 Madrid, Spain \\ e-mail: munozcg@cab.inta-csic.es \\ 2 CNRS-INSU, Institut d'Astrophysique Spatiale, UMR 8617, 91405 Orsay, France \\ 3 Université Paris Sud, Institut d'Astrophysique Spatiale, UMR 8617, bâtiment 121, 91405 Orsay, France \\ ${ }^{4}$ Centre de Recherche sur les Ions, les Matériaux et la Photonique (CEA/CNRS/ENSICAEN/Université de Caen-Basse Normandie), \\ CIMAP - CIRIL - Ganil, Boulevard Henri Becquerel, BP 5133, 14070 Caen Cedex 5, France
}

Received 5 November 2013 / Accepted 30 April 2014

\section{ABSTRACT}

\begin{abstract}
Aims. The main goal of this work is to compare the effects induced in ices of astrophysical relevance by high-energy ions, simulating cosmic rays, and by vacuum ultraviolet (UV) photons.

Methods. This comparison relies on in situ infrared spectroscopy of irradiated $\mathrm{CH}_{3} \mathrm{OH}: \mathrm{NH}_{3}$ ice. Swift heavy ions were provided by the GANIL accelerator. The source of UV was a microwave-stimulated hydrogen flow discharge lamp. The deposited energy doses were similar for ion beams and UV photons to allow a direct comparison.

Results. A variety of organic species was detected during irradiation and later during ice warm-up. These products are common to ion and UV irradiation for doses up to a few tens of eV per molecule. Only the relative abundance of the $\mathrm{CO}$ product, after ice irradiation, was clearly higher in the ion irradiation experiments.

Conclusions. For some ice mixture compositions, the irradiation products formed depend only weakly on the type of irradiation, swift heavy ions, or UV photons. This simplifies the chemical modeling of energetic ice processing in space.
\end{abstract}

Key words. astrochemistry - methods: laboratory: molecular - techniques: spectroscopic - cosmic rays - dust, extinction ultraviolet: ISM

\section{Introduction}

Dust grains covered by ice mantles in interstellar and circumstellar environments are exposed to photons and cosmic rays (ions). In dense interstellar cloud interiors, ice processing is mainly driven by cosmic rays and cosmic-ray-induced secondary UV photons (e.g., Cecchi-Pestellini \& Aiello 1992; Shen et al. 2004). The secondary UV spectrum is simulated well by the microwave-discharge hydrogen flow lamp in the laboratory, with the exception of photon emission at wavelengths below $114 \mathrm{~nm}$ (because of the $\mathrm{MgF}_{2}$ window cutoff, see Cruz-Diaz et al. 2014b, and references therein). As a result of this, a few molecules present in ice mantles such as $\mathrm{CO}$ are not directly dissociated in these experiments and other photon sources are required to explore the extreme-UV and soft X-ray processing of ices, as described for example by Wu et al. (2003) and Chen et al. (2013). Ion irradiation of ices in the laboratory has long been dominated by moderate projectile energies ( $\mathrm{keV}$ to $\mathrm{MeV}$ domain). The results obtained in these experiments were often extrapolated to higher energies (on the order of $1 \mathrm{GeV}$ ) for astrophysical ices. In recent years, some experiments have reached energies near $1 \mathrm{GeV}$ (Seperuelo Duarte et al. 2009, 2010; Pilling et al. 2010a,b; Dartois et al. 2013).

Comparison between the irradiation products made by ions and UV photons is only possible for a reduced number of ice

* Experiments performed at the Grand Accélérateur National d'Ions Lourds (GANIL) in Caen, France. Part of the equipment used in this work has been financed by the French INSU-CNRS program "Physique et Chimie du Milieu Interstellaire" (PCMI). mixtures. A recent introduction to this topic is provided by Islam et al. (2014). Below, we only refer to a few publications in relation to our work. The products of $0.8 \mathrm{MeV}$ protons and UV irradiation were compared for $\mathrm{H}_{2} \mathrm{O}$ ice that contained $\mathrm{CO}_{2}, \mathrm{CH}_{3} \mathrm{OH}$, $\mathrm{CH}_{4}, \mathrm{HCN}$, or $\mathrm{NH}_{3}$ by Moore et al. (2001), Gerakines et al. (2001), and Gerakines et al. (2004). These authors observed the formation of similar products regardless of the nature of the radiation (photons or ions). Recently, $\mathrm{CH}_{3} \mathrm{OH}: \mathrm{N}_{2}$ ice was found to lead to N-bearing products after $200 \mathrm{keV} \mathrm{H}^{+}$ion bombardment, while UV irradiation did not produce such species according to Islam et al. (2014), because of the low photon absorption of $\mathrm{N}_{2}$ in the vacuum-UV range (Cruz-Diaz et al. 2014a). UV irradiation experiments commonly used $\mathrm{H}_{2} \mathrm{O}$-rich ice mixtures that contained $\mathrm{NH}_{3}$ and often $\mathrm{CH}_{3} \mathrm{OH}$ (e.g., Agarwal et al. 1985; Briggs et al. 1992; Bernstein et al. 1995; Bernstein et al. 2002; Muñoz Caro et al. 2002; Muñoz Caro \& Schutte 2003; Meierhenrich et al. 2005; Nuevo et al. 2006). The infrared spectrum of a room-temperature residue made from ion irradiation of an interstellar ice analog, dominated by $\mathrm{H}_{2} \mathrm{O}$ and containing $\mathrm{CH}_{3} \mathrm{OH}$ and $\mathrm{NH}_{3}$ was to our knowledge not reported in the literature. In addition to the references cited above, a residue spectrum that resulted from $0.8 \mathrm{MeV}$ proton bombardment, provided by Marla Moore, is reported in Pendleton \& Allamandola (2002), but it was made starting from a $\mathrm{CH}_{4}: \mathrm{NH}_{3}$ ice composition. Similarly, Strazzulla et al. (2001) showed the infrared spectrum of the room-temperature residue obtained from ion irradiation of $\mathrm{H}_{2} \mathrm{O}: \mathrm{CH}_{4}: \mathrm{N}_{2}$ ice. The room-temperature residue spectrum of $\mathrm{H}_{2} \mathrm{O}: \mathrm{CH}_{3} \mathrm{OH}=1: 0.6$ ice made from $1 \mathrm{MeV}$ proton irradiation was reported by Moore et al. (1996). This spectrum 
looks similar to that obtained from UV irradiation of a similar ice, $\mathrm{H}_{2} \mathrm{O}: \mathrm{CH}_{3} \mathrm{OH}=1: 1$, shown in Fig. 2 (bottom panel) of Muñoz Caro \& Dartois (2009), although there are some differences in the fingerprint region. The main difference is the apparent absence or small depth of the absorption around $1029 \mathrm{~cm}^{-1}$ in the spectrum of Moore et al. (1996). It would therefore be interesting to compare the organic products obtained from ion irradiation of $\mathrm{H}_{2} \mathrm{O}: \mathrm{CH}_{3} \mathrm{OH}: \mathrm{NH}_{3}: \mathrm{CO}: \mathrm{CO}_{2}$ ices with those made by UV irradiation that were previously published. The deposited energy $\left(\mathrm{eV} \mathrm{cm}^{-2}\right)$ in both types of experiments should also be similar for a proper comparison.

The goal of this work is twofold. First, we aim to reproduce the irradiation of ice mantles to study the formation of complex organic molecules by high-energy cosmic rays in dense clouds and circumstellar regions, using the most energetic ions available experimentally. Second, we compare this experiment with a UV-irradiation experiment that uses the same ice mixture and deposited energy dose. The $\mathrm{CH}_{3} \mathrm{OH}: \mathrm{NH}_{3}$ ice mixture was selected because several organic products were identified in UV-irradiation experiments, see Muñoz Caro \& Schutte (2003), and the formation of products can be elucidated using a relatively small set of reactions. Addition of $\mathrm{H}_{2} \mathrm{O}$ to this ice mixture leads to a more complex chemistry (Muñoz Caro \& Schutte 2003; and Öberg et al. 2010) and is left for future work.

\section{Experiments}

\section{Heavy ions}

Ion-irradiation experiments were performed at the heavy-ion accelerator Grand Accélérateur National d'Ions Lourds (GANIL). $\mathrm{Zn}^{26+}$ projectiles were accelerated to $620 \mathrm{MeV}$ on the medium energy exit beam line in November 2010 and $\mathrm{Ne}^{6+}$ projectiles were accelerated to $19.6 \mathrm{MeV}$ in June 2012 at the IRRSUD beam line, respectively. A high-vacuum chamber, with base pressure in the $10^{-7}$ mbar range at room temperature, holding an infraredtransmitting substrate cryocooled at $10 \mathrm{~K}$, on top of which the ice mixture was condensed, was mounted on these beam lines. The ice films were produced by placing the cold window substrate in front of a deposition line where gas mixtures are prepared in the appropriate proportions. The film thickness was chosen to give a high band contrast with respect to the infrared absorptions, without saturating the bands. At such thicknesses, the ion beam passes through the film with an almost constant energy deposition of about $250 \mathrm{eV} / \AA$ (Zn projectile) and $130 \mathrm{eV} / \AA$ (Ne projectile), for a mean density of $0.73 \mathrm{~g} \mathrm{~cm}^{-3}$ for the $\mathrm{NH}_{3}: \mathrm{CH}_{3} \mathrm{OH}$ ice mixture (assuming a density of $0.67 \mathrm{~g} \mathrm{~cm}^{-3}$ for $\mathrm{NH}_{3}$ ice (Satorre et al. 2013) and the liquid value of $0.79 \mathrm{~g} / \mathrm{cm}^{-3}$ for $\mathrm{CH}_{3} \mathrm{OH}$ ). A Nicolet FTIR spectrometer (Magna 550) with a spectral resolution of $1 \mathrm{~cm}^{-1}$ was used. The evolution of the spectra was recorded at several fluences. For more experimental details, see Seperuelo Duarte et al. (2009).

\section{UV photons}

The UV-irradiation experiments were perfomed using the InterStellar Astrochemistry Chamber (ISAC), an ultra-high vacuum setup $\left(2.5-4.0 \times 10^{-11}\right.$ mbar $)$ where an ice sample is made by deposition of a gas mixture onto the cold finger of a closed-cycle helium cryostat at $8 \mathrm{~K}$. The design of the gas line incorporates electrovalves controlled by a quadrupole mass spectrometer, QMS (Pfeiffer Vacuum, Prisma QMS 200). It allows controling the relative proportions of the gas mixture components before and during the deposition. Samples were
UV-irradiated using a microwave-stimulated hydrogen flow discharge lamp that provides a flux of $2.5 \times 10^{14}$ photons $\mathrm{cm}^{-2} \mathrm{~s}^{-1}$ at the sample position with an average photon energy of $8.8 \mathrm{eV}$. After irradiation, the ice is warmed using a constant heating ramp of $1-2 \mathrm{~K} \mathrm{~min}^{-1}$. The ice is monitored by in situ transmittance Fourier transform infrared (FTIR) spectroscopy (Bruker VERTEX 70), while the volatile species are monitored by a second QMS equipped with a Channeltron detector (Pfeiffer Vacuum, Prisma QMS 200). The evolution of the ice was monitored by FTIR spectroscopy in transmittance at a spectral resolution of $2 \mathrm{~cm}^{-1}$, taking spectra before and after the irradiation. For a more detailed description of ISAC, we refer to Muñoz Caro et al. (2010).

\section{Results}

To compare the deposited energies involved across the different experiments, the ion fluence was converted into restricted dose (eV/molecule) using the Stopping and Range of Ions in Matter (SRIM, Ziegler et al. 2008) calculations for a $\mathrm{NH}_{3}: \mathrm{CH}_{3} \mathrm{OH}=$ $1: 1$ ice mixture with an overall density of $0.73 \mathrm{~g} \mathrm{~cm}^{-3}$.

The total column density of the ice deposited in the $\mathrm{UV}$ irradiation experiment, $\mathrm{N}\left(\mathrm{NH}_{3}+\mathrm{CH}_{3} \mathrm{OH}\right)=6 \times$ $10^{17}$ molecules $\mathrm{cm}^{-2}$, was estimated from integration of the CO stretching $\left(v_{8}\right)$ band of methanol absorbing at $1026 \mathrm{~cm}^{-1}$ (d'Hendecourt \& Allamandola 1986), $1.8 \times 10^{-17} \mathrm{~cm} \mathrm{molecule}^{-1}$. The average UV absorption cross-section of the ice mixture is about $7 \times 10^{-18} \mathrm{~cm}^{2}$, based on the values for ammonia ice, $\sim 5 \times 10^{-18} \mathrm{~cm}^{2}$ (Mason et al. 2006; and Cruz-Diaz et al. 2014b), and methanol ice, $\sim 7 \times 10^{-18} \mathrm{~cm}^{2}$ (Cruz-Diaz et al. 2014b). Therefore, about $97 \%$ of the UV photons are absorbed in the ice. For a UV lamp delivering a flux of $2.5 \times 10^{14}$ photons $\mathrm{cm}^{-2} \mathrm{~s}^{-1}$, the average deposited energy is obtained by dividing the total number of absorbed photons by the column density of the deposited ice mixture; it corresponds to $\sim 0.21 \mathrm{eV}$ per molecule per minute of irradiation.

The top panel of Fig. 1 displays the infrared spectra of a $\mathrm{NH}_{3}: \mathrm{CH}_{3} \mathrm{OH}=1: 1$ ice mixture after deposition and during UV irradiation. The total UV irradiation time is given in minutes. A decrease of the initial ice absorptions during UV irradiation is accompanied by the emergence of new absorptions corresponding to the products presented in Table 1. The fourth column indicates the various products in the UV experiment. The $\mathrm{CO}$, $\mathrm{CO}_{2}, \mathrm{H}_{2} \mathrm{CO}$, and $\mathrm{CH}_{4}$ products are also formed by UV irradiation of pure $\mathrm{CH}_{3} \mathrm{OH}$ ice (Gerakines et al. 1996). The evolution of the integrated absorption bands for the main UV-irradiation products is shown in the bottom panel of Fig. 1. Figure 2 displays the warm-up spectra of the irradiated ice. The room temperature spectrum at $300 \mathrm{~K}$ is associated with an organic refractory residue with notable absorption bands at about 3600-2500 (broad), 2929, 2876, 2160, 1723, 1670, 1586, 1454, 1378, 1342, and $1050-1060$ (broad) $\mathrm{cm}^{-1}$. The molecular carriers of these bands are given in Table 2 .

The top panel of Fig. 3 displays the infrared spectra of a $\mathrm{NH}_{3}: \mathrm{CH}_{3} \mathrm{OH}=1: 1$ ice mixture after deposition and during irradiation using $620 \mathrm{MeV} \mathrm{Zn}$ ions. The corresponding fluence, defined as the number of incident ions per $\mathrm{cm}^{2}$, is given for each spectrum. A decrease of the initial ice absorptions during irradiation is accompanied by the emergence of new absorptions corresponding to the products presented in Table 1. The fifth column of Table 1 indicates the various products formed during irradiation. The $\mathrm{CO}, \mathrm{CO}_{2}, \mathrm{H}_{2} \mathrm{CO}$, and $\mathrm{CH}_{4}$ products are also formed by fast heavy ion-irradiation of pure $\mathrm{CH}_{3} \mathrm{OH}$ ice (de Barros et al. 2011). A band near $2234 \mathrm{~cm}^{-1}$ corresponding to $\mathrm{N}_{2} \mathrm{O}$ was not 
Table 1. New bands attributed to irradiation products.

\begin{tabular}{lllll}
\hline \hline Position $^{a}\left(\mathrm{~cm}^{-1}\right)$ & Assignment & Vibration mode & UV after dep. & Zn $(620 \mathrm{MeV})$ \\
\hline 2340 & $\mathrm{CO}_{2}$ & $\mathrm{CO}$ str. & $\times$ & $\times$ \\
2160 & $\mathrm{OCN}^{-}$ & $\mathrm{CN}$ str. & $\times$ & $\times$ \\
2138 & $\mathrm{CO}$ & $\mathrm{CO}$ str. & $\times$ & $\times$ \\
1740 & $\mathrm{C}=\mathrm{O}$ ester/aldehyde & $\mathrm{CO}$ str. & $\times$ & $\times$ \\
1720 & $\mathrm{H}_{2} \mathrm{CO}$ & $\mathrm{CO}$ str. & $\times$ & $\times$ \\
1694 & $\mathrm{HCONH}_{2} ?$ & $\mathrm{CO}$ str. & $\times$ & $\times$ \\
1587 & $\mathrm{COO}^{-}$in carb. ac. salts ${ }^{b, c}$ & $\mathrm{COO}^{-}$asym. str. & $\times$ & $\times$ \\
1498 & $\mathrm{C}_{2} \mathrm{CO}$ & $\mathrm{CH}_{2}$ scis. & $\times$ & $\times$ \\
1385 & $\mathrm{CH}_{3}$ groups & $\mathrm{CH}_{3}$ sym. def. & $\times$ & $\times$ \\
1347 & $\mathrm{COO}^{-}$in carb. ac. salts ${ }^{b, c}$ & $\mathrm{COO}^{-}$sym. str. & $\times$ & $\times$ \\
1303 & $\mathrm{CH}_{4}$ & def. & $\times$ & $\times$ \\
\hline
\end{tabular}

Notes. ${ }^{(a)}$ Position varies sligthly because of the interaction of species within the matrix; ${ }^{(b)}$ Muñoz Caro \& Schutte (2003); ${ }^{(c)}$ Nuevo et al. $(2006)$.
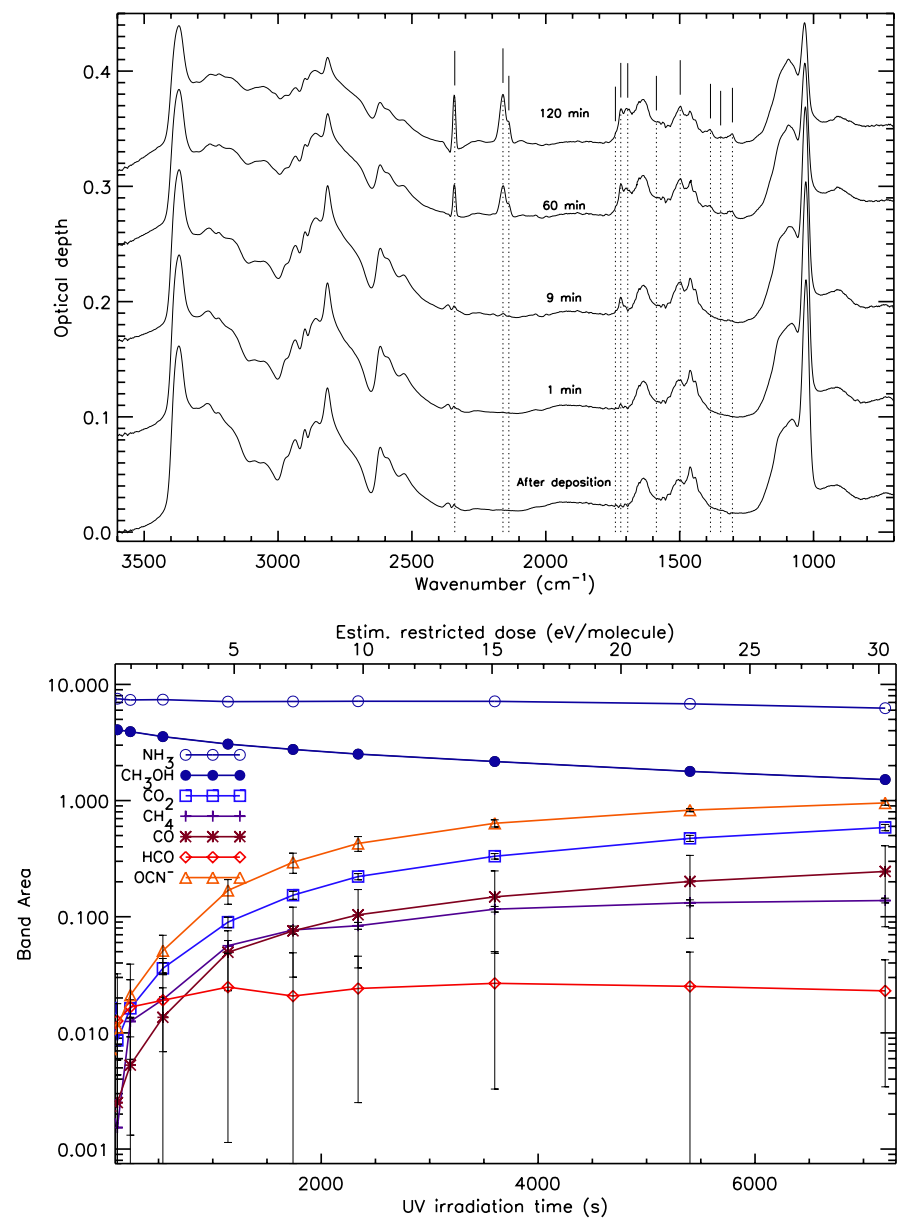

Fig. 1. UV irradiation of $\mathrm{CH}_{3} \mathrm{OH}: \mathrm{NH}_{3}$ ice mixture. The top panel shows the IR spectra at various irradiation times after deposition. The bottom panel shows the decrease of the starting ice bands, corresponding to $\mathrm{NH}_{3}$ and $\mathrm{CH}_{3} \mathrm{OH}$, and the growth of various bands attributed to irradiation products: $\mathrm{CO}_{2}, \mathrm{CH}_{4}, \mathrm{CO}, \mathrm{HCO}$, and $\mathrm{OCN}^{-}$.

observed in our experiment. According to Pilling et al. (2010a), $\mathrm{N}_{2}$ molecules are not easily formed from $\mathrm{NH}_{3}$ and they are required as an intermediate step to synthesize $\mathrm{N}_{2} \mathrm{O}$. The evolution of the integrated absorption bands for the main irradiation products is shown in the bottom panel of Fig. 3. Figure 4 displays the warm-up spectra of the ion irradiated ice. The roomtemperature spectrum at $300 \mathrm{~K}$ is associated with an organic refractory residue with absorption bands at 3600-2500 (broad),

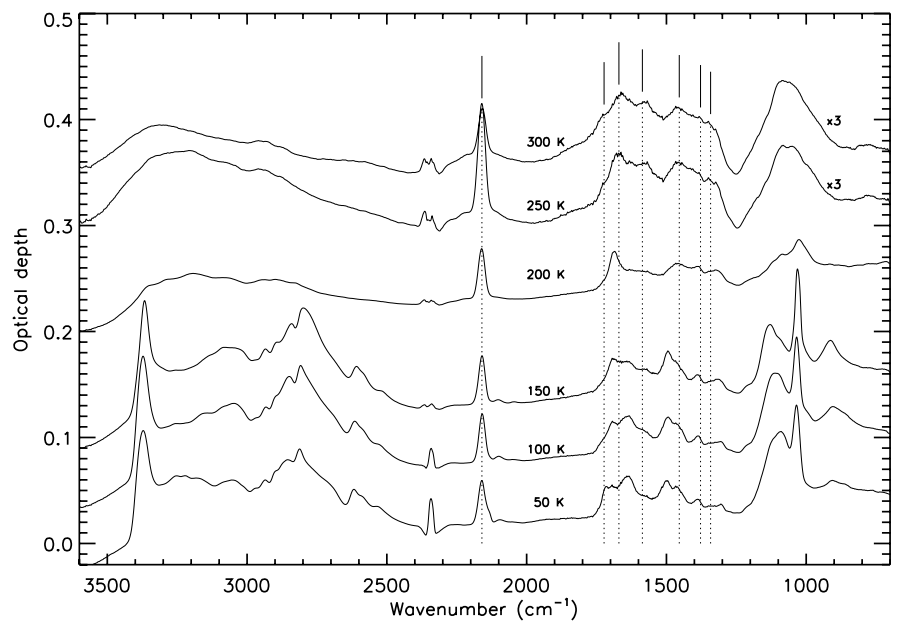

Fig. 2. Warm-up spectra of UV-irradiated $\mathrm{CH}_{3} \mathrm{OH}: \mathrm{NH}_{3}$ ice mixture. The vertical line positions from $2160 \mathrm{~cm}^{-1}$ to $1342 \mathrm{~cm}^{-1}$ are presented and assigned to different vibrations in Table 2. They correspond to the bands identified in the ion-irradiated mixture residues observed at $300 \mathrm{~K}$ for direct comparison with the UV-produced residue at the same temperature.

2929, 2876, 2160, 1723, 1670, 1586, 1454, 1378, 1342, and $1050-1060$ (broad) $\mathrm{cm}^{-1}$. Vertical dotted lines indicate these positions in the figure. The molecular carriers of these bands are given in Table 2 .

A pure $\mathrm{CH}_{3} \mathrm{OH}$ sample was irradiated with the same ions, explaining the formation of some of the species observed in the irradiated mixture (Fig. 5), but not leading to a significant residue during warm-up (Fig. 6).

To complete the set, an irradiation experiment was conducted with $19.6 \mathrm{MeV} \mathrm{Ne}$ ions on a $\mathrm{NH}_{3}: \mathrm{CH}_{3} \mathrm{OH}=1: 1$ ice mixture, to repeat the first experiment using a slightly different stopping power. The infrared spectra during irradiation and the evolution of species with the restricted dose are displayed in Fig. 7. A similar residue (Fig. 8) is obtained during warm-up.

\section{Discussion and astrophysical implications}

The residue spectrum obtained from heavy-ion irradiation (46 MeV ${ }^{58} \mathrm{Ni}^{13+}$ ) of $\mathrm{H}_{2} \mathrm{O}: \mathrm{NH}_{3}: \mathrm{CO}=1: 0.6: 0.4$ (Pilling et al. 2010a) differs from the organic refractory residue produced by UV irradiation of an ice with a similar composition reported in Muñoz Caro \& Schutte (2003). In addition to the different type of irradiation, ions or UV, these differences might be due 
Table 2. Assigned feature carriers of the IR-residue spectrum formed by UV irradiation of $\mathrm{NH}_{3}: \mathrm{CH}_{3} \mathrm{OH}=1: 1$ ice.

\begin{tabular}{|c|c|c|c|c|}
\hline $\begin{array}{c}\text { Position } \\
\mathrm{cm}^{-1}\end{array}$ & Assignment & Vibration mode & UV after dep. & $\mathrm{Zn}(620 \mathrm{MeV})$ \\
\hline $3600-2300$ & R-COOH, alcohols, $\mathrm{NH}_{4}^{+a}$ & OH str., NH str. & $x$ & $x$ \\
\hline 2930 & $-\mathrm{CH}_{2} \mathrm{OH}^{b}$ & $2 v_{19}$ antisym. $-\mathrm{CH}_{2}$ str. & $x$ & $x$ \\
\hline 2875 & $-\mathrm{CH}_{2} \mathrm{OH}^{b}, \mathrm{NH}_{4}^{+a}$ & $v_{18}$ sym. $\mathrm{CH}_{2}$ str., $2 v_{4}$ of $\mathrm{NH}_{4}^{+a}$ & $x$ & $x$ \\
\hline 2160 & $\mathrm{OCN}^{-}$ & $\mathrm{CN}$ str. & $x$ & $x$ \\
\hline 1723 & Aldehydes & $\mathrm{C}=\mathrm{O}$ str. & $x$ & $x$ \\
\hline 1670 & Amides & $\mathrm{C}=\mathrm{O}$ str. & $x$ & $x$ \\
\hline 1586 & $\mathrm{COO}^{-}$in carboxylic acid salts ${ }^{c, d}$ & $\mathrm{COO}^{-}$antisym. str. & $x$ & $x$ \\
\hline 1454 & $\mathrm{NH}_{4}^{+a}, \mathrm{TMTH}^{+e}$ & $v_{4}^{a}$ & $x$ & $x$ \\
\hline 1378 & $\mathrm{CH}_{3}$ groups & $\mathrm{CH}_{\text {scissoring }}{ }^{a}$ & $x$ & $x$ \\
\hline 1342 & $\mathrm{COO}^{-}$in carboxylic acid salts ${ }^{c, d}$ & $\mathrm{COO}^{-}$sym. str. & $x$ & $x$ \\
\hline 1098 & POM-like species ${ }^{c}$ & & $x$ & $x$ \\
\hline 1050 & $\mathrm{CH} 2-\mathrm{OH}$ in primary alcohols & C-O str. & $x$ & $x$ \\
\hline
\end{tabular}

Notes. $\mathrm{TMTH}^{+}$is the protonated form of the trimethylenetriamine, $\mathrm{C}_{3} \mathrm{H}_{10} \mathrm{~N}_{3}$.

References. ${ }^{(a)}$ Wagner \& Hornig (1950); (b) Muñoz Caro \& Dartois (2009); (c) Muñoz Caro \& Schutte (2003); (d) Nuevo et al. (2006); (e) Vinogradoff et al. (2013), and references therein.
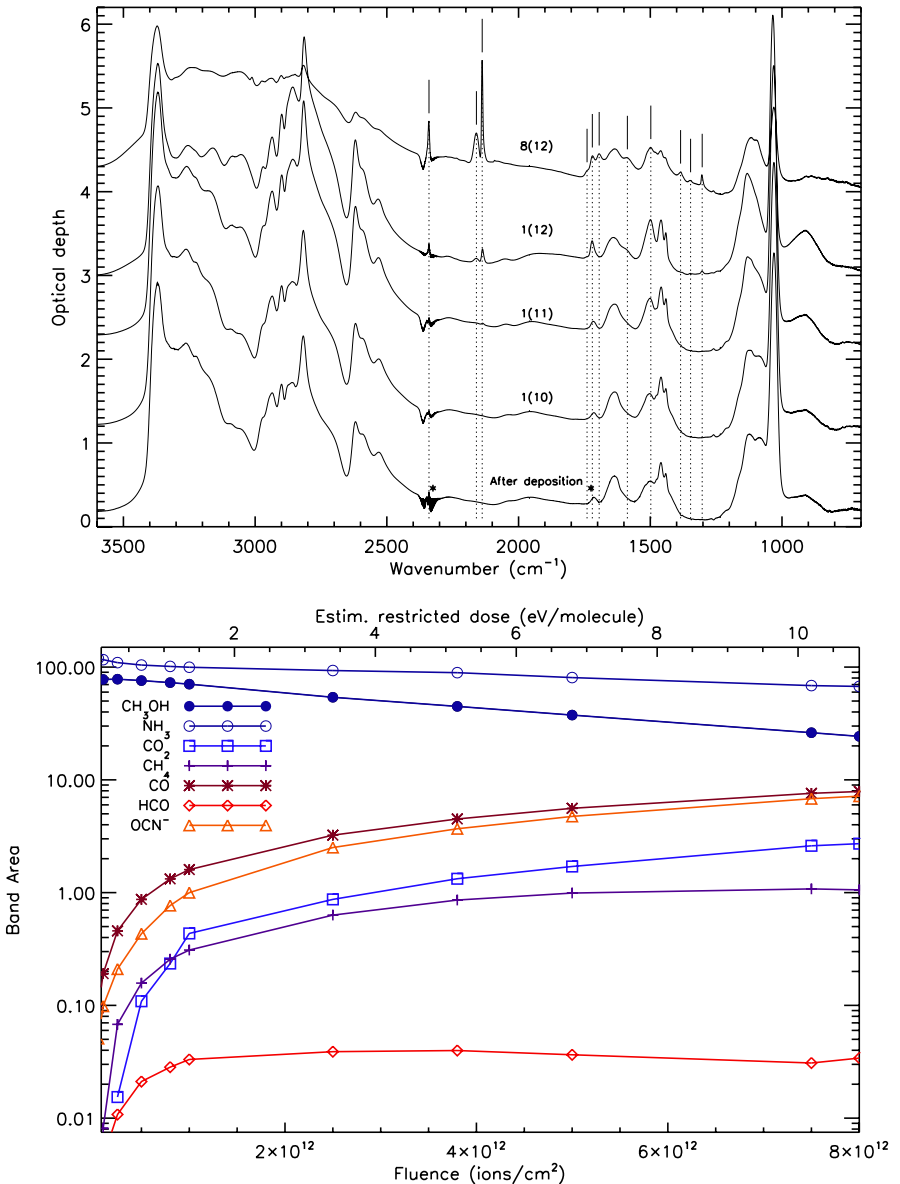

Fig. 3. $620 \mathrm{MeV} \mathrm{Zn}$ ion irradiation of $\mathrm{CH}_{3} \mathrm{OH}: \mathrm{NH}_{3}$ ice mixture. The top panel shows the IR spectra at various irradiation intervals after deposition. The bottom panel shows the decrease of the starting ice bands, corresponding to $\mathrm{NH}_{3}$ and $\mathrm{CH}_{3} \mathrm{OH}$, and the growth of various bands attributed to irradiation products: $\mathrm{CO}_{2}, \mathrm{CH}_{4}, \mathrm{CO}, \mathrm{HCO}$, and $\mathrm{OCN}^{-}$.

to other factors. First, the experimental protocol of these experiments was different: the ion experiment involved irradiation after deposition of the ice, while the UV experiment was performed by simultaneous deposition and irradiation. We found

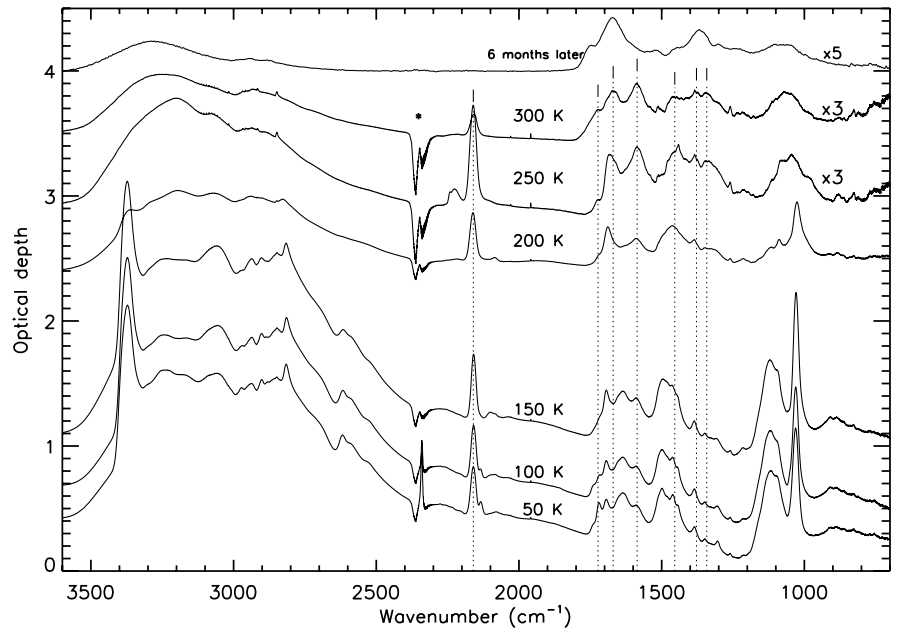

Fig. 4. Warm-up spectra of $620 \mathrm{MeV} \mathrm{Zn} \mathrm{ion} \mathrm{irradiated} \mathrm{CH}_{3} \mathrm{OH}: \mathrm{NH}_{3}$ ice mixture. The vertical line positions from $2160 \mathrm{~cm}^{-1}$ to $1342 \mathrm{~cm}^{-1}$ are presented and assigned to different vibrations in Table 2.

that a new residue made in ISAC by simultaneous deposition and UV irradiation of $\mathrm{NH}_{3}: \mathrm{CH}_{3} \mathrm{OH}=1: 1$ ice, not shown, was very similar to that reported in Fig. 8 of Muñoz Caro \& Schutte (2003) and clearly differs from the one reported in Fig. 2 of our present work, made by irradiation after the ice deposition was complete, thus avoiding irradiation of the molecules in the gas phase before they accrete onto the cold finger. Second, the deposited energy dose in this ion experiment, $5 \times 10^{11}$ (46 $\mathrm{MeV} \mathrm{Ni}$ ions) $\mathrm{cm}^{-2}$, was also different from the UV experiment, 0.24 photon molecule ${ }^{-1}$. Third, the dissociation of the $\mathrm{CO}$ molecule by ions, which is not possible for UV photons of energies $\leq 10.2 \mathrm{eV}$ in a direct way, might also lead to different products. However, this needs to be tested experimentally. Breaking of the $\mathrm{CO}$ occurs if a UV-excited $\mathrm{CO}$ molecule can react with another $\mathrm{CO}$ to form $\mathrm{CO}_{2}+\mathrm{C}$, a process with a very low efficiency for pure CO ice; see, e.g., Muñoz Caro et al. (2010).

The evolution of the abundances for the simple products detected during ion irradiation is similar regardless of the ion source, $620 \mathrm{MeV} \mathrm{Zn}$ or $19.6 \mathrm{MeV}$ Ne ions, see Figs. 3 and 7. Similar products and reaction kinetics during ion exposure were also observed in the $\mathrm{CH}_{3} \mathrm{OH}: \mathrm{NH}_{3}$ and pure $\mathrm{CH}_{3} \mathrm{OH}$ experiments 
G. M. Muñoz Caro et al.: UV vs. high-energy ion irradiation of $\mathrm{CH}_{3} \mathrm{OH}: \mathrm{NH}_{3}$ ice
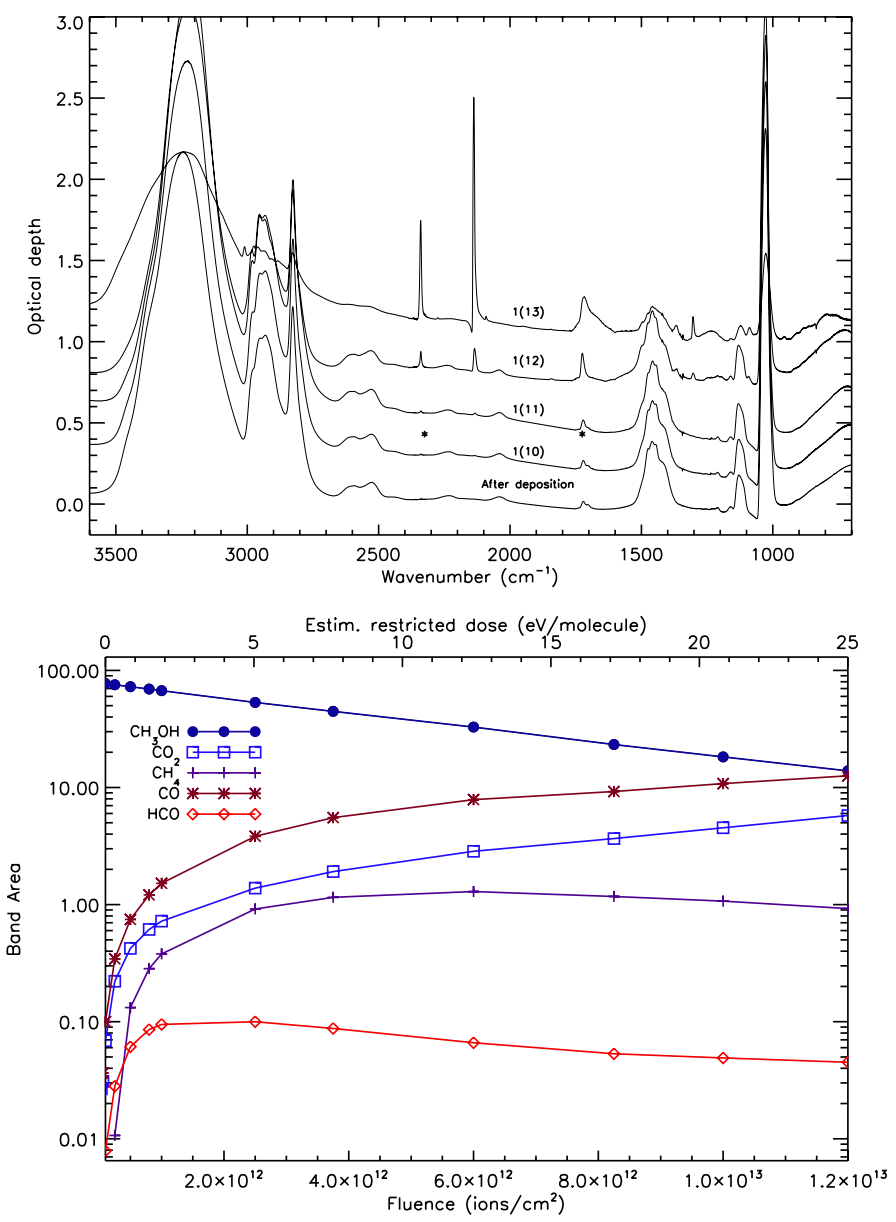

Fig. 5. $620 \mathrm{MeV} \mathrm{Zn}$ ion irradiation of pure $\mathrm{CH}_{3} \mathrm{OH}$ ice. The top panel shows the IR spectra at various irradiation intervals after deposition. The bottom panel shows the decrease of the starting ice $\mathrm{CH}_{3} \mathrm{OH}$ band and the growth of various bands attributed to irradiation products: $\mathrm{CO}_{2}$, $\mathrm{CH}_{4}, \mathrm{CO}$, and $\mathrm{HCO}$.

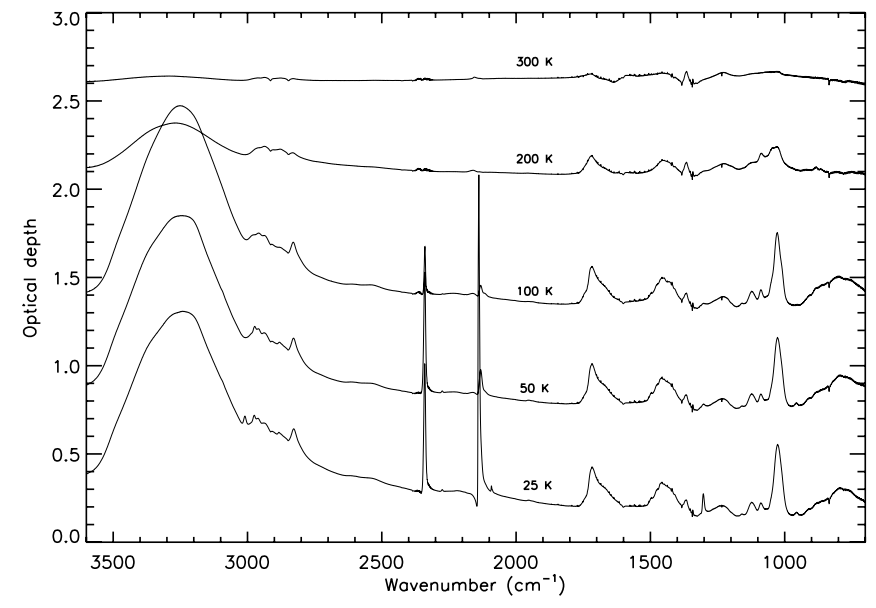

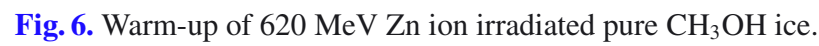

using $620 \mathrm{MeV} \mathrm{Zn}$ ions, with the obvious exception of the $\mathrm{OCN}^{-}$species, Figs. 3 and 5. The relative abundance of $\mathrm{CO}$ in the irradiated ice was higher in the ion experiments, Figs. 3 and 7, than in the UV experiment, Fig. 1, but for comparable restricted dose values the other products displayed similar trends and relative abundances.
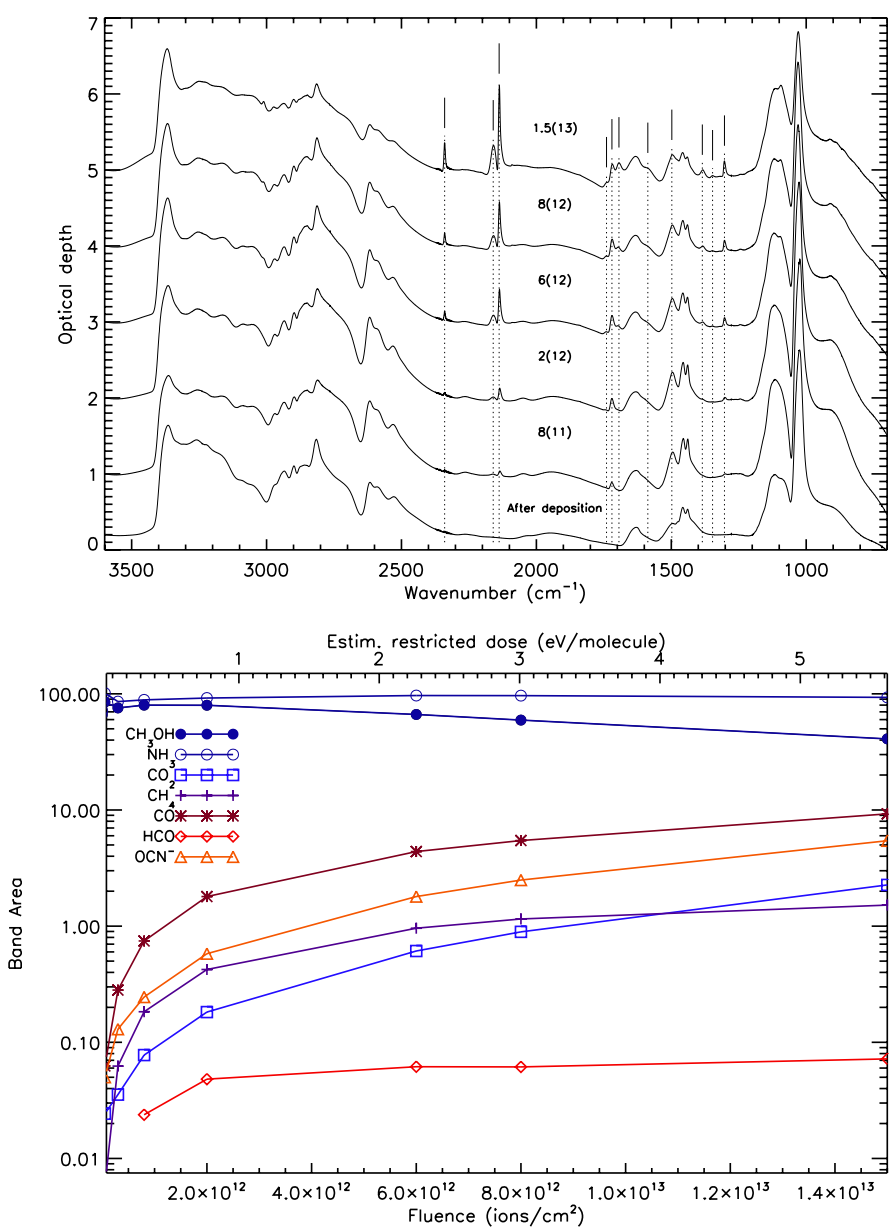

Fig. 7. $19.6 \mathrm{MeV} \mathrm{Ne}$ ion irradiation of $\mathrm{CH}_{3} \mathrm{OH}: \mathrm{NH}_{3}$ ice mixture. The top panel shows the IR spectra at various irradiation intervals after deposition. The bottom panel shows the decrease of the starting ice bands, corresponding to $\mathrm{CH}_{3} \mathrm{OH}$ and $\mathrm{NH}_{3}$, and the growth of various bands attributed to irradiation products: $\mathrm{CO}_{2}, \mathrm{CH}_{4}, \mathrm{CO}, \mathrm{HCO}$, and $\mathrm{OCN}^{-}$.

In our experiments with $\mathrm{CH}_{3} \mathrm{OH}: \mathrm{NH}_{3}$ ice, UV, and swiftion irradiation give, to first order, rise to the same general trend with respect to the residues formed after warm-up to room temperature of the irradiated ices, when normalized to the same dose per molecule. Solid $\mathrm{CH}_{3} \mathrm{OH}$ and $\mathrm{NH}_{3}$ are easily dissociated by vacuum-UV photons. At low temperature, the higher energy density deposited by ions produces small molecules with a higher efficiency than UV photons for species with a higher dissociation energy threshold, or because a cascade of ionizations occur in a small volume simultaneously, see, for example, Table 3 of Seperuelo Duarte et al. (2010) for CO formation cross-sections. On the other hand, the formation of the $\mathrm{CO}, \mathrm{CO}_{2}$, and $\mathrm{OCN}^{-}$species for doses above $\approx 10 \mathrm{eV} /$ molecule is less attenuated for UV irradiation.

In addition to $\mathrm{UV}$ photons, $0.8 \mathrm{MeV}$ proton irradiation of $\mathrm{H}_{2} \mathrm{O}: \mathrm{CO}: \mathrm{CH}_{3} \mathrm{OH}: \mathrm{NH}_{3}$ ice also leads to the formation of hexamethylenetetramine (HMT, $\left.\left[\left(\mathrm{CH}_{2}\right)_{6} \mathrm{~N}_{4}\right]\right)$ (Cottin et al. 2001). After irradiation of an $\mathrm{H}_{2} \mathrm{O}: \mathrm{NH}_{3}: \mathrm{CO}=1: 0.6: 0.4$ ice by $46 \mathrm{MeV}$ $\mathrm{Ni}$ ions, an infrared band observed around $1370 \mathrm{~cm}^{-1}$ was tentatively assigned to HMT (Pilling et al. 2010a). But that identification is not supported by other HMT bands; in particular the about four times more intense HMT band around $1234 \mathrm{~cm}^{-1}$ seems to be absent from their spectrum. In the UV and ion irradiation experiments reported here, the infrared bands characteristic of HMT were not detected in the residue spectra. In the 


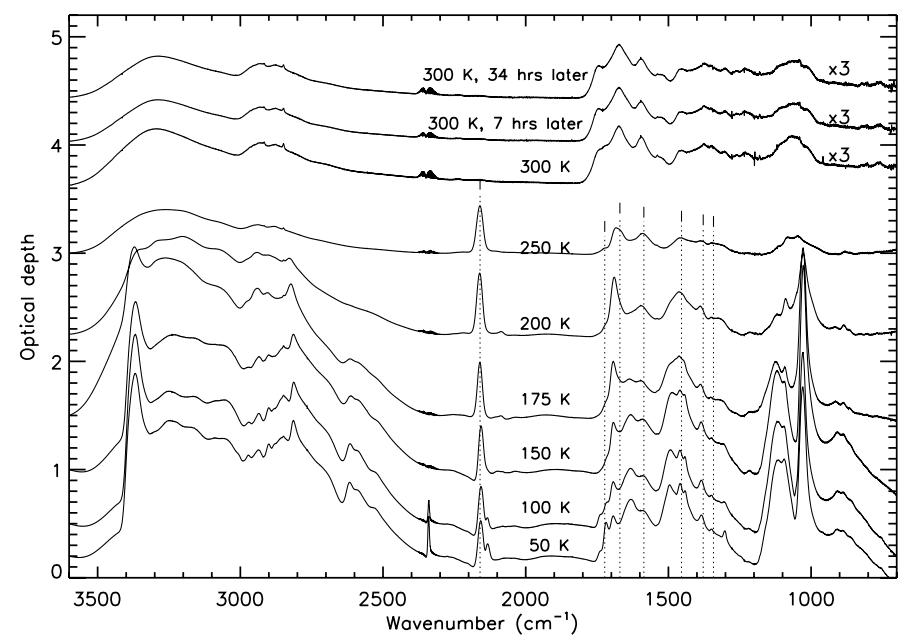

Fig. 8. Warm-up spectra of $19.6 \mathrm{MeV} \mathrm{Ne}$ ion irradiated $\mathrm{CH}_{3} \mathrm{OH}: \mathrm{NH}_{3}$ ice mixture. The vertical line positions from $2160 \mathrm{~cm}^{-1}$ to $1342 \mathrm{~cm}^{-1}$ are presented and assigned to different vibrations in Table 2.

UV experiments, only the simultaneous ice deposition and irradiation led to formation of HMT after warm-up of the ice to room temperature, in line with previous works (Muñoz Caro \& Schutte 2003), but the experiment where irradiation occurred after the ice deposition did not produce HMT, suggesting that gas phase reactions during irradiation might have played a role in the formation of HMT precursors. Since UV irradiation leads to higher amounts of organic products if $\mathrm{H}_{2} \mathrm{O}$ is included in the ice mixture (Muñoz Caro \& Schutte 2003; Öberg et al. 2010), future swift-ion irradiation experiments should incorporate water in the ice to study the possible formation of HMT. In the absence of $\mathrm{H}_{2} \mathrm{O}$, the high concentration of formaldehyde, $\mathrm{H}_{2} \mathrm{CO}$, formed in the $\mathrm{NH}_{3}: \mathrm{CH}_{3} \mathrm{OH}=1: 1$ photolyzed ice, structures related to polyoxymethylene (POM, $\left.\left[\left(-\mathrm{CH}_{2} \mathrm{O}-\right)_{n}\right]\right)$ are expected; such POM-like structures are formed at the expense of HMT and carboxylic acid salts (Muñoz Caro \& Schutte 2003).

Recent publications reported the identification of HMT precursors formed during warm-up of irradiated ices with a different starting composition. Among other ice mixtures, $\mathrm{H}_{2} \mathrm{O}: \mathrm{CH}_{3} \mathrm{OH}: \mathrm{NH}_{3}$ was explored, and the band near $1460 \mathrm{~cm}^{-1}$, previously attributed to $\mathrm{NH}_{4}^{+}$, was identified as the protonated ion trimethyletriamine $\left(\mathrm{TMTH}^{+}, \mathrm{C}_{3} \mathrm{H}_{10} \mathrm{~N}_{3}^{+}\right.$), see Vinogradoff et al. (2013) and references therein. The TMT molecule was identified in residues, along with other N-heterocycles, by gas chromatography coupled to mass spectrometry (Meierhenrich et al. 2005). If these species were present in our residues, which were formed in the absence of $\mathrm{H}_{2} \mathrm{O}$, they did not lead to the formation of HMT in an observable amount. In Table 2 we include $\mathrm{NH}_{4}{ }^{+}$and $\mathrm{TMTH}^{+}$as the possible carriers of the band near $1454 \mathrm{~cm}^{-1}$, although the integrated IR cross-section of $\mathrm{TMTH}^{+}$ would be required for a more quantitative assignment.

The reaction network induced by ion- or photo-processing of the $\mathrm{CH}_{3} \mathrm{OH}: \mathrm{NH}_{3}$ ice mixture, followed by thermal processing, can be highly complex. Even the irradiation of pure $\mathrm{CH}_{3} \mathrm{OH}$ ice with UV photons leads to a complex chemistry (Öberg et al. 2009). It is important to note that the warm-up process followed the same protocol in the UV and the ion experiments reported here because the reactions leading to the more complex species generally occur during heating of the irradiated ice, which allows radicals and ions to recombine and form new molecules. Several selected reactions are provided below, which are expected to play a role in the formation of the detected products.
A similar network was proposed earlier to explain the synthesis of UV-photoproducts in ices, whose functional groups are identified by IR spectroscopy, and some individual molecules were detected by chromatography coupled to mass spectrometry (Agarwal et al. 1985, and references therein; the formation of ammonium salts of carboxylic acids was proposed by Muñoz Caro \& Schutte 2003).

Methanol in the ice can lead to the following reactions:

$\mathrm{CH}_{3} \mathrm{OH}+$ ion/UV $\rightarrow \mathrm{CH}_{3}{ }^{\circ}+\mathrm{OH}^{\circ}$

$\mathrm{CH}_{3} \mathrm{OH}+$ ion/UV $\rightarrow \mathrm{CH}_{2} \mathrm{OH}^{\prime} / \mathrm{OCH}_{3}+\mathrm{H}^{\cdot} \rightarrow \mathrm{H}_{2} \mathrm{CO} \rightarrow \mathrm{HCO} \rightarrow$

$\mathrm{CO}$. The so-formed $\mathrm{CO}$ can be excited by irradiation and react:

$\mathrm{CO}+$ ion/UV $\rightarrow \mathrm{C}+\mathrm{O} / \mathrm{CO}^{*}$, and $\mathrm{CO}^{*}+\mathrm{CO} \rightarrow \mathrm{CO}_{2}+\mathrm{C}$

$\mathrm{CH}_{3} \mathrm{OH}+\mathrm{H}^{\cdot} \rightarrow \mathrm{CH}_{2} \mathrm{OH}^{\cdot}+\mathrm{H}_{2}$, or $\mathrm{H}_{2} \mathrm{CO}+\mathrm{H}^{\cdot} \rightarrow \mathrm{CH}_{2} \mathrm{OH}^{\cdot}$

$\mathrm{CH}_{3}+\mathrm{H}^{\cdot} \rightarrow \mathrm{CH}_{4}$

$\mathrm{HO}^{\circ}+\mathrm{CO} \rightarrow \mathrm{HOOC} \leftrightarrow \mathrm{CO}_{2}+\mathrm{H}$

$\mathrm{H}^{\cdot}+\mathrm{CO} \rightarrow \mathrm{HCO}$

$\mathrm{CH}_{2} \mathrm{OH}^{-}+\mathrm{HCO}^{\circ} \rightarrow \mathrm{HOCH}_{2} \mathrm{CHO}$ (hydroxy-acetaldehyde, formed during warm-up)

$2 \mathrm{CH}_{2} \mathrm{OH} \rightarrow \mathrm{HOCH}_{2} \mathrm{CH}_{2} \mathrm{OH}$ (ethylene glycol, formed during warm-up, Chen et al. 2013)

$\mathrm{CH}_{2} \mathrm{OH}^{-}+\mathrm{COOH}^{-} \rightarrow \mathrm{HOCH}_{2} \mathrm{COOH}$ (glycolic acid, a carboxylic acid, formed during warm-up).

The presence of ammonia in the $\mathrm{CH}_{3} \mathrm{OH}: \mathrm{NH}_{3}$ ice mixture leads to

$\mathrm{NH}_{3}+$ ion/UV $\rightarrow \mathrm{NH}_{2}+\mathrm{H}^{\circ}$.

The $\mathrm{NH}_{x}$ radicals allow the formation of a variety of new species; most of them are produced during the warm-up of the irradiated ice:

$\mathrm{HNCO}$ (from $\mathrm{NH}^{-}+\mathrm{CO}$ ) $+\mathrm{NH}_{3} \rightarrow \mathrm{NH}_{4}^{+} \mathrm{OCN}^{-}$(during warm-up, Mispelaer et al. 2012 and references therein),

$\mathrm{NH}_{2}+\mathrm{CO} \rightarrow \mathrm{NH}_{2} \mathrm{CO}$

$\mathrm{NH}_{2} \mathrm{CO}+\mathrm{H}^{\cdot} \rightarrow \mathrm{HCONH}_{2}$ (formamide)

$2 \mathrm{NH}_{2} \mathrm{CO} \rightarrow \mathrm{H}_{2} \mathrm{NCOCONH}_{2}$ (ethanediamide)

$\mathrm{NH}_{2} \mathrm{CO}+\mathrm{NH}_{2} \rightarrow \mathrm{NH}_{2} \mathrm{CONH}_{2}$ (urea, an amide)

$\mathrm{NH}_{2} \mathrm{CO}+\mathrm{CO}_{2} \mathrm{H} \rightarrow \mathrm{NH}_{2} \mathrm{COCO}_{2} \mathrm{H}$ (oxamic acid)

$\mathrm{CH}_{2} \mathrm{OH}+\mathrm{CONH}_{2} \rightarrow \mathrm{HOCH}_{2} \mathrm{CONH}_{2}$ (hydroxyacetamide)

$\mathrm{HOCH}_{2} \mathrm{COOH}+\mathrm{NH}_{3} \rightarrow\left[\mathrm{NH}_{4}^{+}\right]\left[\mathrm{HOCH}_{2} \mathrm{COO}^{-}\right]$(ammonium salts of carboxylic acids).

The release of molecular ice components into the gas phase by swift-ion sputtering was an important effect, as shown by the strong increase of the gas pressure in the vacuum chamber when the ion beam was on. This desorption is due to electronic sputtering, which strongly depends on the stopping power (Seperuelo Duarte et al. 2009). This effect was not quantified yet for the ice mixtures under investigation here, but it is clearly more efficient than UV-photodesorption; in the latter case such a high increase in the pressure was not observed. The reason for this is that the main effect of vacuum-UV radiation of $\mathrm{CH}_{3} \mathrm{OH}: \mathrm{NH}_{3}$ ice is photodissociation that induces the formation of new species.

Interstellar ices are simultaneously subjected to UV photons and ions. Several publications have provided an estimate of the photon and ion fluxes that dust grains and icy grain mantles experience in interstellar and circumstellar environments, and the energy deposited on the dust by both types of radiation was estimated as well (Cecchi-Pestellini \& Aiello 1992; Shen et al. 2004); the recent publication of Islam et al. (2014) provided an update of these results. Secondary UV photons are expected to deposit a higher energy dose (typically a few $\mathrm{eV} /$ molecule in about one million years) in the ice mantles of external UV-shielded regions (dense clouds) than cosmic ray ions, by a still debated factor of about up to an order of magnitude (see, e.g., Table 3 of Shen et al. 2004), but cosmic 


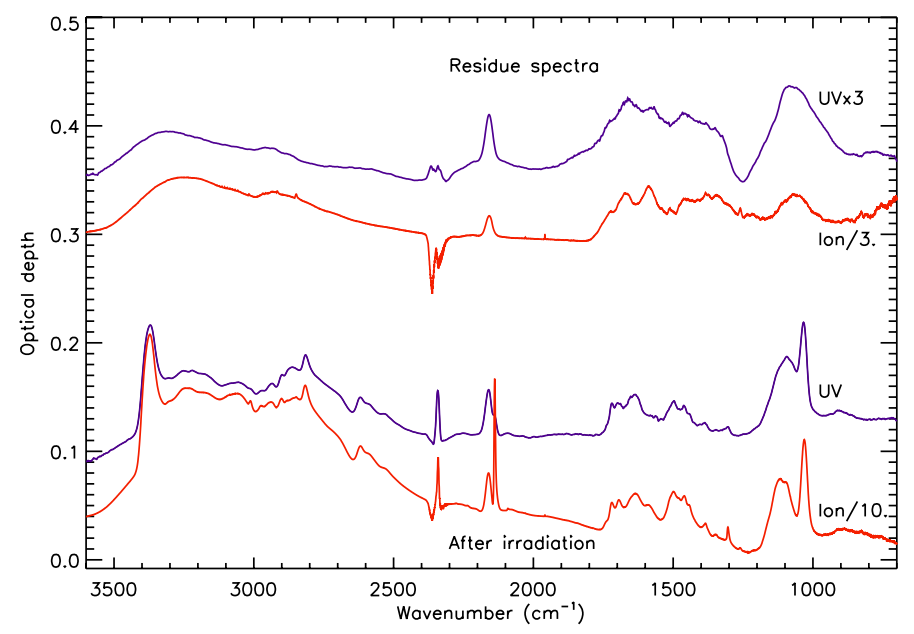

Fig. 9. Comparison of $\mathrm{CH}_{3} \mathrm{OH}: \mathrm{NH}_{3}=1: 1$ ice mixture after UV or $620 \mathrm{MeV}$ ion irradiation. The corresponding residue spectra at room temperature are shown as well.

rays can penetrate deeper into ice mantles (most of them pass through interstellar grains). However, little attention was payed to swift heavy ions since most experiments have dealt with proton or electron bombardment of astrophysical ice analogs. Nevertheless, as mentioned in Sect. 1, these ions are expected to be an important component of cosmic rays in space; in the past five years several experiments simulated their effects in various molecular ice components (Seperuelo Duarte et al. 2009, 2010; Pilling et al. 2010a,b; Dartois et al. 2013). We conclude that in our selected ice mixture where both components, methanol and ammonia, are dissociated easily by vacuum-UV photons, similar photon and ion energy doses led to similar chemical reactions, based on the similarity of the IR spectra of the processed ices. In general, it is therefore not possible to use simple astrophysical molecules (detected in ice mantles or in the gas phase, toward, for instance, hot cores or the higher temperature regions in a protosolar nebula disk, where ice mantles sublimate) as tracers of either UV or ion irradiation. Even the direct dissociation of the most stable molecules such as $\mathrm{N}_{2}$ or $\mathrm{CO}$ in the ice, which cannot be achieved by the vacuum-UV photons in our experiments, can be attained by extreme-UV or X-ray photons (e.g., Wu et al. 2003; and Ciaravella et al. 2012), and therefore the dissociation of these molecules is not intrinsic to ion processing. In addition, to first order, after simultaneous UV/ion processing, a unified organic refractory residue would be formed that is common in the laboratory to UV and ion processing.

\section{Conclusion}

Experiments using a similar ice mixture and energy dose (in $\mathrm{eV}$ molecule ${ }^{-1}$ ) show that UV photon and swift heavy ion irradiation lead to the formation of simple species near $10 \mathrm{~K}$ that are common in both experiments for energy doses up to a few tens of eV per molecule, typical of exposures of millions of years in space. At room temperature, both sources of irradiation formed residues with similar infrared spectral bands, see Table 2 . For a better comparison, Fig. 9 presents the spectra of the irradiated $\mathrm{CH}_{3} \mathrm{OH}: \mathrm{NH}_{3}=1: 1$ ice mixture using UV or $620 \mathrm{MeV} \mathrm{Zn}$ ions, and the corresponding residues that remained at room temperature. The synthesis of these products is expected to follow a complex set of reactions, which were discussed in Sect. 4. This finding has important implications for models of the chemistry in icy grain mantles in space. We mentioned in Sect. 1 that other works comparing protons and UV photons arrived at a similar conclusion. Both methanol and ammonia are easily dissociated by ions or vacuum-UV photons, forming simple radicals and fragments that react during warm-up. The warm-up rate was the same in our experiments. The immediate question is, therefore, whether a similar chemistry can be expected, as was observed experimentally. A priori, some differences can be envisioned. Among the products, $\mathrm{CO}$ was observed in the irradiated ice of our ion and UV experiments. Similar to $\mathrm{N}_{2}$, see Islam et al. (2014) and references therein for differences between ions and vacuum-UV photons in irradiated ices containing $\mathrm{N}_{2}$, the $\mathrm{CO}$ molecule can be directly dissociated by ions but not by UV with photon energies below $10.2 \mathrm{eV}$, which is the case of the hydrogen UV lamp that we employed. Incoming ions will gradually dissociate the previously formed $\mathrm{CO}$, while a large part of the $\mathrm{CO}$ generated by UV will remain intact upon further UV irradiation (not all, because photodesorption of $\mathrm{CO}$ operates in the top monolayers (e.g., Muñoz Caro et al. 2010) and CO can participate in the ice photo- and thermal chemistry by reacting with another UV-excited CO molecule or a different species). Ions can not only dissociate $\mathrm{CO}$ ice molecules directly, they can also be sputtered along with other species. Therefore, we did not foresee a similar evolution of the $\mathrm{CO}$ abundance curve in the irradiated ice using different sources. As a comparison, clear differences were observed among products formed by either X-ray or UV-irradiation of pure CO ice (Ciaravella et al. 2012).

To study the observed similarity between vacuum-UV and swift ion ice processing, the formation of ice irradiation products by swift ions will be explored in the near future using different ice mixtures that include $\mathrm{H}_{2} \mathrm{O}$. If, as is the case for the studied $\mathrm{CH}_{3} \mathrm{OH}: \mathrm{NH}_{3}$ ice mixture, the organic residue formed by swift ion irradiation of ice is similar to that obtained by UV photon irradiation, the use of swift ions will allow us to grow thicker residues and perform analyses that require higher amounts of material than previous studies such as nuclear magnetic resonance (NMR), which will provide an access to a complementary identification of functional groups present in residues. Furthermore, a chromatographic analysis of thick residues made by swift-ion processing of ice might also lead to the detection of new molecular components in the organic residues.

The synthesis of complex organic species results from both UV- and ion-processing experiments followed by warm-up. These species might be present in circumstellar regions and some comets, and were likely delivered to the primitive Earth.

Acknowledgements. We are grateful to T. Been, C. Grygiel, T. Madi, I. Monnet and J. M. Ramillon for their invaluable support. This work has been supported by the European Community as an Integrating Activity "Support of Public and Industrial Research Using Ion Beam Technology (SPIRIT)" under EC contract no. 227012, the Spanish MICINN/MINECO under projects AYA2011-29375 and CONSOLIDER grant CSD2009-00038.

\section{References}

Agarwal, V. K., Schutte, W. A., Greenberg, J. M., et al. 1985, Origins of Life and Evolution of the Biosphere, 16, 21

Allamandola, L. J., Sandford, S. A., \& Valero, G. J. 1988, Icarus, 76, 225

Bernstein, M. P., Sandford, S. A., Allamandola, L. J., Chang, S., \& Scharberg, M. A. 1995, ApJ, 454, 327

Bernstein, M. P., Dworkin, J. P., Sandford, S. A., Cooper, G. W., \& Allamandola, L. J. 2002, Nature, 416, 401

Briggs, R., Ertem, G., Ferris, J. P., et al. 1992, Origins of Life and Evolution of the Biosphere, 22, 287

Cecchi-Pestellini, C., \& Aiello, S. 1992, MNRAS, 258, 125

Chen, Y.-J., Ciaravella, A., Muñoz Caro, G. M., et al. 2013, ApJ, 778, 162

Ciaravella, A., Jiménez-Escobar, A., Muñoz Caro, G. M., et al. 2012, ApJ, 746, L1 
Cottin, H., Szopa, C., \& Moore, M. H. 2001, ApJ, 561, L139

Cruz Diaz, G. A., Muñoz Caro, G. M., Chen, Y.-J., \& Yih, T.-S. 2014a, A\&A, 562, A 120

Cruz Diaz, G. A., Muñoz Caro, G. M., Chen, Y.-J., \& Yih, T.-S. 2014b, A\&A, 562, A119

Dartois, E., Ding, J. J., de Barros, A. L. F., et al. 2013, A\&A, 557, A97

de Barros, A. L. F., Domaracka, A., Andrade, D. P. P., et al. 2011, MNRAS, 418, 1363

D’Hendecourt, L. B., \& Allamandola, L. J. 1986, A\&ASS, 64, 453

Gerakines, P. A., Schutte, W. A., \& Ehrenfreund, P. 1996, A\&A, 312, 289

Gerakines, P. A., Moore, M. H., \& Hudson, R. L. 2001, J. Geophys. Res. Planets, 106, 33381

Gerakines, P. A., Moore, M. H., \& Hudson, R. L. 2004, Icarus, 170, 202

Islam, F., Baratta, G. A., Palumbo, M. E. 2014, A\&A, 561, A73

Mason, N. J., Dawes, A., Holtom, P. D., et al. 2006, Faraday Discuss., 133, 311

Meierhenrich, U. J., Muñoz Caro, G. M., Schutte, W. A., et al. 2005, Chem. Eur. J., 11, 4895

Mispelaer, F., Theule, P., Duvernay, F., Roubin, P., \& Chiavassa, T. 2012, A\&A, 540, A40

Moore, M. H., Ferrante, R. F., \& Nuth III, J. A. 1996, Planet. Space Sci., 44, 927

Moore, M. H., Hudson, R. L., \& Gerakines, P. A. 2001, Spectrochim. Acta Part A, 57, 843

Muñoz Caro, G. M., \& Dartois, E. 2009, A\&A, 494, 109

Muñoz Caro, G. M., \& Schutte, W. A. 2003, A\&A, 412, 121
Muñoz Caro, G. M., Meierhenrich, U. J., Schutte, W. A., et al. 2002, Nature, 416, 403

Muñoz Caro, G. M., Jiménez-Escobar, A., Martín-Gago, J. Á., et al. 2010, A\&A, 522, 108

Nuevo, M., Meierhenrich, U. J., Muñoz Caro, G. M., et al. 2006, A\&A, 457, 741

Oberg, K. I. R., Garrod, R. T., van Dishoeck, E. F., \& Linnartz, H. 2009, A\&A, 504,891

Öberg, K. I. R., van Dishoeck, E. F., Linnartz, H., \& Andersson, S. 2010, ApJ, 718,832

Pendleton, Y. J., \& Allamandola, L. J. 2002, ApJS, 138, 75

Pilling, S., Seperuelo Duarte, E., da Silveira, E. F., et al. 2010a, A\&A, 509, A87

Pilling, S., Seperuelo Duarte, E., Domaracka, A., et al. 2010b, A\&A, 523, A77

Satorre, M. Á., Leliwa-Kopystynski, J., Santonja, C., \& Luna, R. 2013, Icarus, 225,703

Seperuelo Duarte, E., Boduch, P., Rothard, H., et al. 2009, A\&A, 502, 599

Seperuelo Duarte, E., Domaracka, A., Boduch, P., et al. 2010, A\&A, 512, A71

Shen, C. J., Greenberg, J. M., Schutte, W. A., \& van Dishoeck, E. F. 2004, A\&A, 415, 203

Strazzulla, G., Baratta, G. A., \& Palumbo, M. E. 2001, Spectrochim. Acta Part A, 57,825

Vinogradoff, V., Fray, N., Duvernay, F., et al. 2013, A\&A, 551, A128

Wu, C. Y. R., Judge, D. L., Cheng, B.-M., et al. 2003, J. Geophys. Res. (Planets), 108,13

Ziegler, J. F., Biersack, J. P., \& Ziegler, M. D. 2008, SRIM, the Stopping and Range of Ions in Matter (Chester, Maryland: SRIM Co.) 